\title{
Article
}

\section{ANGI - Anorexia Nervosa Genetics Initiative}

\author{
Cynthia Bulik ${ }^{1,2}$, Martin Kennedy ${ }^{3}$ and Tracey Wade ${ }^{4}$ \\ ${ }^{1}$ Center of Excellence for Eating Disorders, Department of Psychiatry, University of North Carolina, Chapel Hill, NC, USA, ${ }^{2}$ Department of Medical Epidemiology \\ and Biostatistics, Karolinska Institutet, Stockholm, Sweden, ${ }^{3}$ Department of Pathology and Biomedical Science, University of Otago, Christchurch, New Zealand \\ and ${ }^{4}$ Discipline of Psychology, Flinders University, South Australia, Australia
}

\begin{abstract}
Identification of genetic variants associated with eating disorders is underway. The Anorexia Nervosa Genetics Initiative, an initiative of the Klarman Family Foundation, has contributed to advancing the field, yielding a large-scale genome-wide association study published in Nature Genetics. Eight genetic variants significantly associated with anorexia nervosa were identified, along with patterns of genetic correlations that suggest both psychiatric and metabolic origins of this serious and life-threatening illness. This article details the role of Professor Nick Martin in contributing to this important collaboration.
\end{abstract}

Keywords: Anorexia nervosa; genetic variants; eating disorders

(Received 11 February 2020; accepted 26 March 2020)

\section{Cynthia Bulik}

Nick was a force of nature when it came to recruiting participants for the Anorexia Nervosa Genetics Initiative (ANGI) in Australia (Kirk et al., 2017; Thornton et al., 2018). This study, funded by the Klarman Family Foundation, formed the backbone of the Nature Genetics paper 'Genome-wide association study identifies eight risk loci and implicates metabo-psychiatric origins for anorexia nervosa' (Watson et al., 2019). Even though eating disorders is not his primary area of expertise, Nick managed to garner support from clinicians, families and individuals with the illness around Australia to build a community of participation that made the study possible. It is not always easy as an outsider to step into our field and have an immediate positive impact, but Nick did. His success with ANGI is the main reason why Australia is now a site for our next major endeavor, the Eating Disorders Genetics Initiative (EDGI). I imagine he will have the same impact again! Nick is my role model for collegiality, productivity and generativity in the latter stages of one's career.

Perhaps even more impressive is a trait that I knew Nick had within his field, but I was astonished to see that it generalized outside of behavior genetics (BG). Nick travels a lot, so he is often circadianly challenged. This means that he may occasionally doze off during talks. I had witnessed his uncanny ability to sleep through a talk only to wake up during the Q\&A period to ask the single most pertinent question - almost as if he were sleeping with one ear open. I wrote this off to just being a giant in the BG field, until I saw him do it at an eating disorders conference on a topic that was completely outside of his area of expertise! The only other person I have ever seen be able to pull this off is Lindon Eaves

Address for correspondence: Tracey Wade, Email: tracey.wade@flinders.edu.au

Cite this article: Bulik C, Kennedy M, and Wade T. (2020) ANGI - Anorexia Nervosa Genetics Initiative. Twin Research and Human Genetics 23: 135-136, https://doi.org/ $10.1017 /$ thg. 2020.24 and I am convinced it is a sign of genius. Or it is a total con and he just wants us to think that he is sleeping!

\section{Martin Kennedy}

I had known Nick as a force in the field of human genetics for many years, but not directly worked with him until the ANGI study came along. I recall Cindy emailed me one day to ask if anyone was doing eating disorders research in New Zealand, and I suspect this may have been partly prompted by Nick. I am a geneticist and knew little about eating disorders, but had a very good colleague in Jenny Jordan, a clinical psychologist, who did. Jenny and I wrote and won a small research grant that funded us to get going and contribute samples to the Australian arm of the study, and of course this brought us into close proximity with Nick and his team. Once Nick realized we were committed to this, he created the opportunity for us to continue contributing samples and provided resources for us to achieve that. It was a steep learning curve for us, but Nick's generosity, wisdom and enthusiasm ensured we worked hard to meet the study goals. Of course, this is something so many will have experienced and must surely be part of the secret of Nick's enormous success. He is adept at charming, motivating, exciting, and if need be, pressurizing people to perform. He is wonderfully collegial and witty and has a highly tuned ability to rapidly sort the wheat from the chaff. Combined with his expansive knowledge and prodigious work output, this makes for an extraordinary package.

Nick called me a year or two ago in conjunction with a depression genome-wide association study (GWAS) he was running, and which he had hoped we would be able to contribute to (sadly we were unable to). He said to me then that he got great pleasure from organizing and leading large GWAS consortia, realized it was something he was very good at, and felt this might be something of a lasting legacy from the later years of his career. There is already no doubt that this is true. 
I should add it is never dull being at a conference when Nick is present. At question time he can be provocative or challenging, but always with good humor and sincerity. He is also generous with praise and support, particularly for young investigators. More than anything, his love of science, and of discussing science, shines through. He is an extraordinary role model for all of us!

We are very proud that New Zealand is part of the EDGI Team, but I do not think we would have been able to take this on without the ongoing support, expertise and resources that Nick and his Queensland Institute of Medical Research Berghofer team have provided. I suspect this is probably the case for many smaller groups contributing to large GWAS studies in this part of the world.

\section{Tracey Wade}

I first met Nick on the banks of the Torrens River outside of the University of Adelaide, almost 30 years ago, to discuss his involvement as a supervisor of my $\mathrm{PhD}$, to be conducted at Flinders University. I had the idea that I would like to investigate the role of genes in eating disorders, as there was very little work in this area. As a clinical psychologist I really had no idea what I was talking about, but Nick was immediately enthusiastic, even more so when he found out that my husband was a member of the Liberal Party. Despite his best efforts to induce me to relocate to Brisbane, I stayed in Adelaide for the duration of the thesis. Looking back now as a seasoned PhD supervisor, I marvel anew at Nick's generosity and support over that time. He has been one of a handful of extremely influential supervisors in my life, of whom Cindy Bulik was another, who challenged me to aim higher and do better and answer questions with scientific rigor, a legacy that has stood me well over my career, and continues to inspire me in the mentoring I give to my own research students.

Nick's mentorship did not stop with my PhD. He actively pursued a postdoctoral opportunity for me with Kenneth Kendler and Cynthia Bulik at the Virginia Institute for Psychiatric and
Behavioral Genetics of Virginia Commonwealth University. In recent years, he supported my nomination to the Academy of Social Sciences in Australia. Over my career, we have published many papers together, mainly in the behavioral genetics of eating disorders, culminating in the Nature Genetics ANGI paper last year (Watson et al., 2019).

The work that Nick has been involved in has made a major contribution to moving the field from blaming the family for causing an eating disorder to starting to appreciate the complexity of the various genetic and (mainly) nonshared environmental risk factors. This has had a critical impact on the field, allowing us to devise nonblaming therapies and work with families as partners in treatment.

Nick is an impressive poster boy for valuing the progress of science above all else and paying no heed to the territorial and ownership issues that can plague some scientific endeavor. $\mathrm{He}$ was Open Science before it was even a thing. Interactions with him are always energizing (even, as Cindy points out, when he is ostensibly sleeping). Those of us who are rather less brilliant and extroverted can feel rather drained after some encounters, but they always make our work richer, and inspire us to do better.

\section{References}

Kirk, K. M., Martin, F. C., Mao, A., Parker, P., Maguire, S., Thornton, L. M., \& Martin, N. G. (2017). The Anorexia Nervosa Genetics Initiative: study description and sample characteristics of the Australian and New Zealand arm. Australian and New Zealand Journal of Psychiatry, 51, 583-594. https://doi.org/10.1177/0004867417700731

Thornton, L. M., Munn-Chernoff, M. A., Baker, J. H., Juréus, A., Parker, R., Henders, A.K., \& Bulik, C. M. (2018). The Anorexia Nervosa Genetics Initiative (ANGI): overview and methods. Contemporary Clinical Trials, 74, 61-69. https://doi.org/10.1016/j.cct.2018.09.015

Watson, H., Yilmaz, Z., Thornton, L. M., Hübel, C., Coleman, J. R. I., Bryois, J., \& Bulik, C. M. (2019). Anorexia nervosa genome-wide association study identifies eight loci and implicates metabo-psychiatric origins. Nature Genetics, 51, 1207-1214. https://doi.org/10.1038/s41588-019-0439-2 